\section{Australian Journal of \\ Crop Science}

\title{
Expression of rice genes homologous of Arabidopsis genes previously related to drought tolerance
}

\author{
Fernanda Raquel Martins Abreu, ${ }^{1}$, Karinne Evaristo de Deus ${ }^{2}$, Wendell Jacinto Pereira ${ }^{2}$, Ricardo \\ Diógenes Dias Silveira ${ }^{3}$, Rosana Pereira Vianello ${ }^{3}$, Claudio Brondani ${ }^{3 *}$
}

\author{
${ }^{1}$ School of Agronomy and Food Engineering, Federal University of Goias, Goiania, GO, 74001-970, Brazil \\ ${ }^{2}$ Institute of Biological Science, Federal University of Goias, Goiania, GO, 74001-970, Brazil \\ ${ }^{3}$ Biotechnology Laboratory, Embrapa Arroz e Feijão, Santo Antonio de Goias, GO, 75375-000, Brazil
}

\author{
*Corresponding author: claudio.brondani@embrapa.br
}

\begin{abstract}
The identification and validation of candidate genes related to traits of interest is a time consuming and expensive process and the homology among genes from different species can facilitate the identification of genes of the target species from the genomic information of a model species. This study aimed to quantify the expression of homologous rice genes previously related to drought tolerance in Arabidopsis. Five genes (CPK6, PLD, GluR2, CesA8, and EIN2) were identified in rice by the homology of the amino acid sequence between rice and Arabidopsis. The genotypes Douradão (drought tolerant) and Primavera (drought susceptible) were subjected to a water deficit experiment, and subsequently evaluated for gene expression by qPCR for the five homologous and Lsil genes. The qPCR analysis clearly showed that the five homologous genes were expressed in rice, which is an indication that these genes could preserve their function in rice as a response to drought. In Douradão, of the five homologous genes, all but $O s G l u R 2$ displayed an increase in the average expression in drought treatment when compared to the control, while in Primavera, the average expression of the five genes did not differ between the control and drought treatment. In Douradão, the $O s P L D \alpha 1$, which showed the higher expression level in drought in relation to the control (10.82 times), significantly increased the gene expression in the leaf and root tissues as a response to drought, in both vegetative and reproductive stages, whereas in Primavera, this gene was suppressed in both tissues and stages under drought. Therefore, the $O S P L D \alpha 1$ gene was the most important in relation to drought response and is an interesting candidate for further studies in developing rice cultivars that are more tolerant to this stress.
\end{abstract}

Keywords: Oryza sativa; abscisic acid; gene homology; quantitative PCR; yield.

Abbreviations: ABA_abscisic acid; ACT_actin; Ces_cellulose synthase; CPK or CDPK_calcium-dependent protein kinase; eEF_eukaryotic elongation factor; EIN_ethylene insensitive; GAPDH_glyceraldehyde-3-phosphate dehydrogenase; GLR_GluRrelated; GluR_glutamate receptor; Lsi_low silicon rice; PA_phosphatidic acid; PLD_phospholipase D.

\section{Introduction}

Water will become increasingly scarcer in the scenario of climate change. Even in the most productive crop environments, short periods of water deficiency are responsible for considerable reductions in both seed and biomass yield each year (Cominelli et al., 2013). Drought is a major limitation for rice production in upland rainfed ecosystems, and the estimated global rice yield lost to drought is approximately 18 million tonnes annually, which equates to about $4 \%$ of the total rice production (Kamoshita et al., 2008). Amongst cereals, rice, as a paddy field crop, is particularly susceptible to water stress, and it is estimated that $50 \%$ of the global rice production is affected by drought.

Major research efforts are directed towards understanding the mechanism of plant responses to drought stress and aiming to identify gene products that confer adaptation to water deficit. Molecular mechanisms of water stress response have been investigated primarily in the model plant species Arabidopsis thaliana. Upon exposure to drought-stress conditions, many stress-related genes are induced, and their products are thought to function as cellular protectors from stress-induced damage (Ambavaram et al., 2014). Plant stress response is a complex process encompassing a series of interlinked steps, including perception of stress stimuli, relay of the stress signal and initiation of the adaptive response (Hu and Xiong, 2014). Cellular responses to stress include adjustments of the membrane system, modifications of the cell wall architecture, and changes in cell cycle and cell division. Stress-inducible genes comprise of genes involved in direct protection from stress, including the synthesis of osmoprotectants, detoxifying enzymes, and transporters, as well as genes that encode regulatory proteins such as transcription factors, protein kinases, and phosphatases (Krasensky and Jonak, 2012). Over the course of evolution, plants have developed sophisticated mechanisms that allow adaptation and survival during water deficit periods. These mechanisms serve as candidate pathways for enhanced drought stress tolerance engineering. It has been well documented that upon exposure to abiotic stresses, plants undergo transcriptional reprogramming of a large spectrum of stress-responsive genes, leading to an array of physiological and metabolic changes (Xian et al., 2014). Orthologous genes are defined as genes in different species that have evolved only through speciation events (Dessimoz et al., 2012; Holme et al., 2012); they usually preserve the same function, and can 
even compare metabolic pathways between different species (Fang et al., 2010). However, given the unknown nature of the evolutionary relations between the genes of each gene cluster, it is preferable to use the term homologous rather than the strict definition of orthologous to describe the related genes of different species in gene clusters (Patel et al., 2012). The discovery of Arabidopsis homologous genes in rice related to drought tolerance can represent a saving of both time and of financial resources, especially in the validation of the gene function. In this study, five genes previously related to drought tolerance in Arabidopsis were chosen and their homologs in rice were identified. Additionally, the Lsi-lgene, involved in silicon transport in rice (Ma et al., 2006), was previously related to an increase in pest and disease resistance in rice and Arabidopsis (Ma and Yamaji, 2008), and in this work, was used as a parameter for the rice gene expression.

The Arabidopsis $P L D \alpha 1$ gene (phospholipase D alpha 1, AT3G15730) encodes the phospholipase Dalenzyme, which promotes stomatal closure and reduces water loss (Sang et al., 2001) mediated by abscisic acid (ABA) (Guo and Wang, 2012; Wang, 2014). The Arabidopsis AtCPK6 gene (Calcium-dependent protein kinase, AT2G17290) is a member of the Calcium dependent protein kinase (CDPK) family, it has an important function in stomatal guard cell ion channel regulation that transduces stomatal ABA signaling (Mori et al., 2006), and was related to drought tolerance in Arabidopsis plants overexpressing this gene (Xu et al., 2010). The AtCesA 8 gene (cellulose synthase catalytic subunit A, AT4G18780), related to cellulose synthesis, is one of the 10 CesA genes identified in Arabidopsis and rice (Yan et al., 2007). The disruption of the AtCesA8 gene resulted in an increase in drought tolerance in Arabidopsis (Chen et al., 2005). The AtGluR2 gene (Glutamate receptor 2, AT4G35290) is a homolog of the mammalian ionotropic glutamate receptor gene (Kim et al., 2001). This gene belongs to the GLR gene family, and even though the mode of action of GLR is unknown, the role in drought tolerance, found in rice and Arabidopsis, may be related to the regulation of carbon/nitrogen metabolism, ABA biosynthesis, and $\mathrm{Ca}^{2+}$ induced stomatal closure (Lu et al., 2014). The EIN2 gene (Ethylene insensitive 2, AT5G03280) regulates the plant's response to osmotic and salt stress through an ABAdependent pathway in Arabidopsis (Wang, 2007). EIN2 is a central signaling component required for all ethylene responses, given that the mutants with loss-of-function (ein2 mutants) show complete ethylene insensitivity ( $\mathrm{Li}$ et al., 2013). ABA and ethylene appear to interact to regulate plant stress responses, but the molecular connections between the ethylene effects on ABA responsiveness are still not wellcharacterized. This study aimed to quantify the expression of five rice homolog genes previously related to drought tolerance in Arabidopsis.

\section{Results and Discussion}

Photosynthesis and the related carbon metabolism are primarily affected by drought stress, especially in reproductive stages, thereby reducing grain yield. The understanding of this complex interaction can provide the genetic tools to maintain the potential yield (Ambavaram et al., 2014). Molecular mechanisms of water stress response have been investigated primarily in the model plant species Arabidopsis. The rice homolog genes were identified from the amino acid sequences of the chosen Arabidopsis droughtrelated genes. The qPCR analysis showed that the five homologous rice genes from Arabidopsis were expressed, which is an indication that these genes could preserve a putative function as a response to drought.

\section{Drought experiment}

Significant yield difference was observed in Douradão and Primavera cultivated under drought when compared to their respective controls in the reproductive stage (Table 1). However, there was no statistical difference in yield between Douradão and Primavera when considering water availability and plant stage. In relation to the vegetative stage, even the productivity gap between the drought and control treatments was not significant for Douradão and Primavera, probably because the plants were able to recover from the effects of drought before the harvest period.

\section{Differential gene expression}

The leaf tissue showed the highest number of genes with increased expression under drought treatment when compared to the control treatment (occurred in 63\% of cases), more often in Douradão (75\%), whereas in the root tissue it was observed the highest number of genes with an expression reduction under drought (74\%), more often in Primavera $(57 \%)$. The reproductive stage showed the highest number of genes with increased expression $(62 \%)$, more frequent in Douradão $(67 \%)$, and also the highest number with reduced expression, more frequent in Primavera $(64 \%)$. The genes that more often increased the expression in the drought treatment, considering the results for both Douradão and Primavera, were OsPLD 1 , OsCesA4 and OsEIN2 (four combinations of tissues and stages), whereas OsGluR2 and OsCPK5 more often had reduced expressions (also in four combinations) (Table 2).

\section{OsPLDa1}

In drought tolerant Douradão, the $O S P L D \alpha 1$ significantly increased gene expression in leaf and root tissues was observed when a water deficit was applied, in both the vegetative and reproductive stages (Table 2), as previously reported by Bargmann et al. (2009) in tomato plants. However, in the susceptible Primavera cultivar this gene was suppressed in both tissues and stages under drought. The differential gene expression observed between Douradão and Primavera, in both the vegetative and reproductive stages, indicates that the $O S P L D \alpha 1$ gene is in fact directly involved in drought tolerance in rice. Singh et al. (2012), in a microarray experiment, also observed the upregulation of this gene in plants submitted to drought. On average, Douradão showed an expression level 10.92 times higher in drought treatment in relation to the control, while in Primavera the expression was 2.4 times lower in drought than in the control. In Douradão, the highest levels of $O s P L D \alpha 1$ expression in roots were observed in the vegetative stage and in leaves in the reproductive stage $(\sim 38 \mathrm{x}$ higher than those observed in their respective control plants). This expression variation may be explained based on the ABA synthesis pattern, which at an early stage of water shortage in the soil, is synthesized in the roots and transported through the xylem to the shoot as a sign of stress to regulate stomatal movement and the expression of genes related to drought tolerance. However, when the adequate transportation of water is hampered, which can lead to a lack of water in the shoot or make the plants suffer constant stress, it is possible that ABA can be synthesized in the shoot and then be transported to the roots (Chen et al., 2005). The cloning, transformation and overexpression of this 
Table 1. Grain yield of Douradão and Primavera cultivars for $100 \%$ and $50 \%$ water availability treatments.

\begin{tabular}{|c|c|c|c|c|c|c|c|c|c|c|c|c|c|c|}
\hline \multirow[b]{2}{*}{ Treatment } & \multicolumn{7}{|c|}{ Vegetative stage } & \multicolumn{7}{|c|}{ Reproductive stage } \\
\hline & \multicolumn{3}{|c|}{ Douradão } & \multicolumn{3}{|c|}{ Primavera } & \multirow{2}{*}{$\begin{array}{l}\mathrm{a} \\
n s\end{array}$} & \multicolumn{3}{|c|}{ Douradão } & \multicolumn{3}{|c|}{ Primavera } & $\mathrm{a}$ \\
\hline $100 \%$ & 48.8 & \pm & 6.0 & 43.7 & \pm & 8.903 & & 59.7 & \pm & 13.8 & 59.7 & \pm & 14.9 & $n s$ \\
\hline $50 \%$ & 41.6 & \pm & 13.00 & 41.9 & \pm & 15.279 & $n s$ & 10.0 & \pm & 7.0 & 17.6 & \pm & 12.7 & $n s$ \\
\hline
\end{tabular}

* Statistically significant value by Tukey test $(\mathrm{p}<0.05) .{ }^{a}$ Comparison between different genotypes in the same treatment. ${ }^{\mathrm{b}}$ Comparison between the same genotype in different treatments. $n s$ - not significant.

Table 2. Average relative quantification (RQ) of OsPLD $\alpha 1$, OsCesA4, OsGluR2, OsCPK5, OsEIN2, and Lsil genes in Douradão and Primavera genotypes in different stages, irrigation (50\% and 100\% water availability), and tissues.

\begin{tabular}{|c|c|c|c|c|c|c|c|c|}
\hline \multirow{2}{*}{ Gene } & \multirow{2}{*}{ Treatment } & \multirow{2}{*}{ Tissue } & \multicolumn{3}{|c|}{ RQ Vegetative Stage } & \multicolumn{3}{|c|}{ RQ Reproductive Stage } \\
\hline & & & Douradão & Primavera & a & Douradão & Primavera & a \\
\hline \multirow{6}{*}{$O s P L D \alpha 1$} & $100 \%$ & \multirow{2}{*}{ Leaf } & $1.00 \pm 0.00$ & $1.45 \pm 0.15$ & $*$ & $0.53 \pm 0.03$ & $2.98 \pm 0.35$ & $*$ \\
\hline & $50 \%$ & & $1.58 \pm 0.23$ & $1.71 \pm 0.17$ & $n s$ & $20.01 \pm 0.49$ & $2.15 \pm 0.23$ & $*$ \\
\hline & \multirow{4}{*}{$\begin{array}{c}100 \% \\
50 \%\end{array}$} & b & * & $n s$ & & $*$ & $*$ & \\
\hline & & \multirow{2}{*}{ Root } & $1.52 \pm 0.08$ & $1.32 \pm 0.25$ & $n s$ & $0.91 \pm 0.03$ & $2.67 \pm 0.54$ & $*$ \\
\hline & & & $3.98 \pm 0.04$ & $0.85 \pm 0.02$ & $*$ & $1.19 \pm 0.04$ & $0.52 \pm 0.06$ & $*$ \\
\hline & & $\mathrm{b}$ & $*$ & $*$ & & $*$ & $*$ & \\
\hline \multirow{6}{*}{ OsCesA4 } & $100 \%$ & \multirow{2}{*}{ Leaf } & $1.00 \pm 0.00$ & $0.92 \pm 0.15$ & $n s$ & $2.80 \pm 0.25$ & $19.48 \pm 0.29$ & $*$ \\
\hline & $50 \%$ & & $12.5 \pm 1.09$ & $1.05 \pm 0.09$ & $*$ & $7.20 \pm 0.54$ & $13.56 \pm 1.79$ & $*$ \\
\hline & \multirow{4}{*}{$\begin{array}{c}100 \% \\
50 \%\end{array}$} & b & * & $n s$ & & * & $*$ & \\
\hline & & \multirow{2}{*}{ Root } & $29.39 \pm 0.30$ & $28.65 \pm 0.40$ & $*$ & $18.12 \pm 2.77$ & $19.36 \pm 1.92$ & $n s$ \\
\hline & & & $19.48 \pm 0.04$ & $11.95 \pm 1.88$ & $*$ & $39.50 \pm 0.04$ & $74.34 \pm 3.78$ & $*$ \\
\hline & & b & $*$ & $*$ & & $*$ & $*$ & \\
\hline \multirow{6}{*}{ OsGluR2 } & $100 \%$ & \multirow{2}{*}{ Leaf } & $1.00 \pm 0.00$ & $1.73 \pm 0.22$ & $*$ & $1.69 \pm 0.09$ & $5.61 \pm 0.20$ & $*$ \\
\hline & $50 \%$ & & $0.87 \pm 0.06$ & $1.92 \pm 0.03$ & $*$ & $2.47 \pm 0.18$ & $8.64 \pm 0.67$ & $*$ \\
\hline & \multirow{4}{*}{$\begin{array}{c}100 \% \\
50 \%\end{array}$} & b' & * & $n s$ & & $*$ & * & \\
\hline & & \multirow{2}{*}{ Root } & $0.80 \pm 0.05$ & $0.71 \pm 0.03$ & $*$ & $5.71 \pm 0.49$ & $4.60 \pm 0.52$ & $*$ \\
\hline & & & $0.62 \pm 0.04$ & $0.72 \pm 0.04$ & $*$ & $2.25 \pm 0.04$ & $1.20 \pm 0.06$ & $*$ \\
\hline & & b & * & $n s$ & & * & $*$ & \\
\hline \multirow{6}{*}{ OsCPK5 } & $100 \%$ & \multirow{2}{*}{ Leaf } & $1.00 \pm 0.00$ & $0.65 \pm 0.04$ & $*$ & $3.03 \pm 0.52$ & $8.08 \pm 0.45$ & * \\
\hline & $50 \%$ & & $0.99 \pm 0.08$ & $0.81 \pm 0.12$ & $n s$ & $6.76 \pm 0.58$ & $1.68 \pm 0.05$ & $*$ \\
\hline & \multirow{4}{*}{$\begin{array}{c}100 \% \\
50 \%\end{array}$} & b & $n s$ & $n s$ & & * & * & \\
\hline & & \multirow{2}{*}{ Root } & $3.70 \pm 0.32$ & $3.29 \pm 0.30$ & $n s$ & $7.55 \pm 0.81$ & $8.17 \pm 1.29$ & $n s$ \\
\hline & & & $7.66 \pm 0.04$ & $2.13 \pm 0.11$ & $*$ & $1.55 \pm 0.04$ & $5.72 \pm 0.16$ & $*$ \\
\hline & & b & * & $*$ & & * & $*$ & \\
\hline \multirow{6}{*}{ OsEIN2 } & $100 \%$ & \multirow{2}{*}{ Leaf } & $1.00 \pm 0.00$ & $1.41 \pm 0.10$ & $*$ & $2.52 \pm 0.18$ & $1.35 \pm 0.17$ & $*$ \\
\hline & $50 \%$ & & $1.17 \pm 0.13$ & $1.53 \pm 0.17$ & $*$ & $4.30 \pm 0.35$ & $2.83 \pm 0.06$ & * \\
\hline & & b' & $n s$ & $n s$ & & * & * & \\
\hline & $100 \%$ & \multirow{2}{*}{ Root } & $1.19 \pm 0.02$ & $0.65 \pm 0.12$ & $*$ & $2.14 \pm 0.10$ & $1.25 \pm 0.12$ & $*$ \\
\hline & $50 \%$ & & $1.56 \pm 0.04$ & $0.17 \pm 0.01$ & $*$ & $1.10 \pm 0.04$ & $2.36 \pm 0.64$ & $*$ \\
\hline & & $\mathrm{b}$ & * & $*$ & & $*$ & $*$ & \\
\hline \multirow{6}{*}{ Lsil } & $100 \%$ & \multirow{2}{*}{ Leaf } & $1.00 \pm 0.00$ & $1.60 \pm 0.38$ & $*$ & $6.88 \pm 0.39$ & $64.86 \pm 14.06$ & * \\
\hline & $50 \%$ & & $3.20 \pm 0.59$ & $2.61 \pm 0.58$ & $n s$ & $14.15 \pm 1.61$ & $6.06 \pm 1.07$ & $*$ \\
\hline & & b & * & $*$ & & $*$ & $*$ & \\
\hline & $100 \%$ & Root & $114.96 \pm 19.99$ & $93.29 \pm 11.07$ & $n s$ & $24.60 \pm 1.35$ & $64.53 \pm 19.49$ & $*$ \\
\hline & $50 \%$ & KoOt & $108.43 \pm 0.04$ & $34.11 \pm 4.78$ & $*$ & $11.39 \pm 0.04$ & $63.83 \pm 10.02$ & * \\
\hline & & & $n s$ & $*$ & & $*$ & $n s$ & \\
\hline
\end{tabular}

*Statistically significant value by Tukey test $(\mathrm{p}<0.05)$. ${ }^{\mathrm{a} C o m p a r i s o n}$ between different genotypes in the same treatment. ${ }^{\mathrm{b}}$ Comparison between the same genotype in different treatments. $n s$ - not significant.

Table 3. Arabidopsis genes used to identify the respective rice homologous genes.

\begin{tabular}{|c|c|c|c|c|c|c|c|}
\hline Gene & $\mathrm{ID}^{\mathrm{a}}$ & Source & Action & Function & Rice ID ${ }^{b}$ & Rice Gene & e-value \\
\hline AtCPK6 & At2G17290 & $\begin{array}{l}\text { Mori et al. } \\
(2006)\end{array}$ & $\begin{array}{l}\text { Calcium sensor that transduces stomatal } \\
\text { ABA signaling }\end{array}$ & Stomatal closure & LOC_Os02g46090 & $O s C P K 5$ & $10^{-209}$ \\
\hline$A t P L D \alpha$ & At3G15730 & $\begin{array}{l}\text { Sang et al. } \\
(2001)\end{array}$ & Phospholipase expression & Stomatal closure & LOC_Os01g07760 & $O s P L D \alpha 1$ & 0.0 \\
\hline AtGluR2 & At4G35290 & $\begin{array}{l}\text { Kim et al. } \\
(2001)\end{array}$ & $\begin{array}{l}\text { Signal transduction and calcium } \\
\text { homeostasis }\end{array}$ & Stomatal closure & LOC_Os02g02540 & OsGluR2 & $10^{-244}$ \\
\hline AtCesA8 & At4g18780 & $\begin{array}{l}\text { Chen et al. } \\
(2005)\end{array}$ & Signaling pathway mediated by ethylene & $\begin{array}{l}\text { Cellulose } \\
\text { synthesis }\end{array}$ & LOC_Os01g54620 & OsCesA4 & 0.0 \\
\hline AtEIN2 & At5g03280 & $\begin{array}{l}\text { Wang et al. } \\
(2007)\end{array}$ & Ethylene signal transduction & $\begin{array}{l}\text { Regulation of leaf } \\
\text { senescence }\end{array}$ & LOC_Os07g06130 & OsEIN2 & $10^{-206}$ \\
\hline$L s i 1^{\mathrm{c}}$ & - & $\begin{array}{l}\text { Ma et al. } \\
(2006)\end{array}$ & Aquaporin & $\begin{array}{l}\text { Biotic stress } \\
\text { resistance }\end{array}$ & LOC_Os02g51110 & OsNIP & - \\
\hline
\end{tabular}

${ }^{\mathrm{a}}$ The Arabidopsis gene identity was obtained in The Arabidopsis Information Resource (TAIR); ${ }^{\mathrm{b}}$ The rice gene identity was obtained in Rice Genome Annotation Project (RGAP); ${ }^{\mathrm{c}} \mathrm{Lsi}-1$ is a rice gene selected as a control for the rice gene expression analysis. 
Table 4. Primer pairs for expression analysis by RT-qPCR

\begin{tabular}{|c|c|c|c|c|c|}
\hline Gene & Primer sequences $\left(5^{\prime} \rightarrow 3^{\prime}\right)$ & $\operatorname{Tm}\left({ }^{\circ} \mathrm{C}\right)$ & Amplicon & E & $\mathrm{R}^{2}$ \\
\hline \multirow{2}{*}{ OsPLD $\alpha 1$} & CACCAAAATGATGATAGTTGACG & 59.2 & \multirow{2}{*}{$100 \mathrm{bp}$} & \multirow{2}{*}{$104 \%$} & \multirow{2}{*}{0.9946} \\
\hline & CATGGCGATCTCAGAGTCC & 62.3 & & & \\
\hline \multirow{2}{*}{ OsCesA4 } & TTGCACGATATGGAGATGGA & 58.4 & \multirow{2}{*}{$112 \mathrm{bp}$} & \multirow{2}{*}{$97 \%$} & \multirow{2}{*}{0.9944} \\
\hline & GACAGAACAGTATTCGCAGTGA & 60.8 & & & \\
\hline \multirow{2}{*}{ OsGluR2 } & CGAGTTTGACGCAGCAATAG & 60.4 & \multirow{2}{*}{$102 \mathrm{bp}$} & \multirow{2}{*}{$99 \%$} & \multirow{2}{*}{0.9998} \\
\hline & GCCAAGATAACCAAGCCAGA & 60.4 & & & \\
\hline \multirow{2}{*}{ OsCPK5 } & TGTTCTTCAAGCCTGGTCAA & 58.4 & \multirow{2}{*}{$120 \mathrm{bp}$} & \multirow{2}{*}{$105 \%$} & \multirow{2}{*}{0.9902} \\
\hline & GAATCACACCAGCTGTCCAA & 60.4 & & & \\
\hline \multirow{2}{*}{ OsEIN2 } & CGATGATTTTTGGGATAGCA & 56.3 & \multirow{2}{*}{$101 \mathrm{bp}$} & \multirow{2}{*}{$101 \%$} & \multirow{2}{*}{0.9953} \\
\hline & TGGTAGCAGATTAGGAACAACG & 60.8 & & & \\
\hline \multirow{2}{*}{ Lsil } & ATGCCTACCATGTACTACG & 58 & \multirow{2}{*}{$75 \mathrm{bp}$} & \multirow{2}{*}{$101 \%$} & \multirow{2}{*}{0.9916} \\
\hline & CGACACGACCTTCTTGAG & 59.9 & & & \\
\hline
\end{tabular}

Tm: Melting temperature; E: efficiency.

gene in rice could reduce this water loss and increase drought tolerance, as observed in the overexpression of AtPLD $\alpha 1$ in Arabidopsis (Mishra et al., 2006) and Brassica napus (Lu et al. 2013), and the TaPLD $\alpha$ wheat gene in Arabidopsis (Wang et al., 2014).

\section{OsCesA4}

The Douradão cultivar increased the expression of the OsCesA4 gene in leaf tissue in the two stages of development and in root tissue in the reproductive stage, while Primavera only increased its expression in root tissue in the reproductive stage (Table 2). On average, both Douradão and Primavera showed greater expression in drought treatments in relation to control treatments, 4.5 and 1.53, respectively. Since this gene is related to cellulose synthesis, its increased expression in leaf tissue may be the result of changes that occur due to drought such as leaf rolling. Yang et al. (2014) reported that the knock-down of the OsMYB103L gene, which encodes a transcription factor related to the expression of the CesA gene family, decreased the cellulose synthesis, the mechanical strength in leaves, and the expression levels of the CesA genes. Shobbar et al. (2008) identified a reduction in leaf growth related to ABA action after the occurrence of water deficit and increased expression of the OsCesA4 gene in rice, which is essential for secondary cell wall formation and for the strength of the stem. The overexpression of this gene could maintain optimal levels of dry matter and may result in little reduction in photosynthesis under drought thus preserving the yield potential of these materials.

\section{OsGluR2}

In Douradão, the $O s G l u R 2$ gene was down-regulated in the vegetative stage both in the leaves and in the root and upregulated in the leaves and down-regulated in the roots in the reproductive stage when a water deficit was applied. Both Douradão and Primavera showed, on average, a reduction in expression levels when comparing the drought and control treatments, 1.42 and 1.59 times, respectively. Lu et al. (2014) found a higher expression of the OSGLR2 gene in leaf tissue, resulting in increased drought tolerance in rice which overexpresses the gene (LOC_Os09g26160), which is not the same gene used in our study (LOC_Os02g02540). The OsGLR2 action mechanism has not yet been elucidated, and additional studies should be made before indicating this gene as a candidate for the development of more drought-tolerant cultivars.

\section{OsCPK5}

In Douradão, this gene was induced by drought in the vegetative stage in the root, and leaf tissue in the reproductive stage, being repressed in the root in the reproductive stage. On average, Douradão showed an expression level 1.38 times higher in drought treatment in relation to the control, while in Primavera the expression was 2.15 times lower in drought than what was expressed in the control. This pattern of expression was also observed in the $O S P L D \alpha 1$ gene, and may be due to the fact that both OsPLD $\alpha 1$ and $O s C P K 5$ are involved in ABA-induced stomatal closure (Mori et al., 2006; Uraji et al., 2012) by transduction of stress signals (Xiong et al., 2002). The combined action of these genes could increase the drought tolerance by the generation of genetically modified rice plants overexpressing them, as observed for OsCPK5 in Arabidopsis (Xu et al., 2010) and OsPLD $\alpha 1$ in tobacco (Sang et al., 2001).

\section{OsEIN2}

The OsEIN2 expression in Douradão presented the same pattern of $O s C P K 5$ expression in the vegetative and reproductive stages. In Primavera, the OSEIN2 gene was suppressed at the root in the vegetative stage and induced in the leaf and root in the reproductive stage. On average, both Douradão and Primavera showed a higher expression in drought treatment in relation to the control, 1.17 and 1.34 times, respectively. Comparing the expression of all genes, OsEIN2 was the most responsive to drought in Primavera, and may have been decisive in the drought tolerance of this cultivar. The EIN2 gene, as well as PLD $\alpha 1$ and CPK5, also acts in the regulation of stomatal closure, but unlike these two genes, in an ABA-independent route. Watkins et al. (2014) observed that the ethylene overexpression increased the production of flavonols, suppressing the accumulation of ROS, and decreasing the stomatal ABA-dependent closing rate, i.e., acting in modulating responses. $\mathrm{ABA}$ and ethylene interactions are complex and not well-characterized, appearing to interact to regulate plant stress responses. For example, ABA limits ethylene production in water stressed plants, whereas ethylene antagonizes the stomatal response to ABA under oxidative stress (Thole et al., 2014). This indicates that both genes should be manipulated independently in rice, due to the probable antagonistic effect of the overexpression of EIN2 and PLD 1 .

\section{Lsi1}

Lsil $(O s N I P 2 ; 1)$ is the first silicon (silicic acid) transporter identified in plants, which belongs to the nodulin 26-like intrinsic membrane protein (NIP) subfamily of aquaporins. NIPs are unique to plants, and to date have been identified nine members in Arabidopsis and 13 members in rice (Mitani et al., 2008). Silicon (Si) is recognized in helping plants to 
overcome biotic stresses, such as rice blast (Cai et al., 2008) and abiotic stresses, such as drought (Chen et al., 2011). This gene was identified in rice and has been used in this study due to the gene expression control in relation to the other rice gene homologs from Arabidopsis genes. On average, Douradão showed an expression level 1.67 times higher in the drought treatment in relation to the control, while in Primavera the expression was 3.76 times lower in the drought treatment than in the control. In Douradão, the Lsil gene was upregulated in the drought treatment of leaf tissue in the two stages of development, and downregulated in root tissue in the reproductive stage. In Primavera, the gene was upregulated in leaf tissue in the vegetative stage and downregulated in the reproductive stage, whereas the root tissue was downregulated in the vegetative stage. The upregulated expression in the Lsil leaf tissue confirmed the action of this gene in the drought tolerance of rice.

\section{Materials and Methods}

\section{Rice homologous gene identification from Arabidopsis genes}

Five Arabidopsis genes related to drought tolerance were identified and chosen for this study. The amino acid sequences of these genes were used for TBLASTN searches on the Rice Genome Annotation Project (RGAP) website (http://rice.plantbiology.msu.edu/), and five rice homologues were identified (Table 3). The Lsi-1 gene was selected as a control for the rice gene expression analysis (Ma et al., 2006).

\section{Plant material and drought experiment}

The drought-tolerant Douradão upland rice cultivar and drought-sensitive Primavera cultivar were studied under drought treatments in a greenhouse at Embrapa Rice and Beans (Santo Antônio de Goiás, Brazil), in the 2013/2014 growing season. For the experiment, approximately ten seeds of the cultivars were sown in pots, and after germination, five randomly chosen plants were maintained in each pot. Water restriction was applied in two periods: in period 1 the interruption in irrigation occurred between vegetative stage V3 (in accordance with the classification of Counce et al., 2000), (17 DAS - Days After Sowing - for Douradão and 15 DAS for Primavera) and V6 (35 DAS for Douradão and 34 DAS for Primavera); and in period 2, the interruption in irrigation began in reproductive stage R3 (panicle emergence - 55 DAS for Douradão and 64 DAS for Primavera) through R6 (milky grain - 66 DAS for Douradão and 75 DAS for Primavera). During these two periods, two irrigation regimes were used: Group A (control group) - a set of plants with the availability of water set at field capacity (FC); and Group B a set of plants exposed to $50 \%$ of FC. Once $50 \%$ of the plants from each cultivar reached the V3 vegetative state (the beginning of the first cycle of water deficiency), irrigation was interrupted in such a way that the different water regimes could be reached in the soil until the V6 vegetative stage. Irrigation continued normally for the set of plants exposed to the second period of water deficiency until more than $50 \%$ of the plants in this set of pots reached reproductive stage R3, at which time water restriction was enforced and lasted until stage R6. The duration of the drought stress was six days.

The experimental design was a split-plot randomized block. Six replicates were used for each cultivar and for each cycle of water deficiency. Of the six replicates, three pots were used for the sampling of the plant material, and three pots were maintained until the end of the rice cycle to determine the productivity. Replicates were established according to the water regime, genotype, and water-deficiency cycle, for a total of two plots (Periods 1 and 2) with 48 pots each. To establish the amount of water per pot for each water regime, the field capacity (FC) of the soil was determined, defined as the maximum water content retained by the soil after the excess has been drained, recording the maximum mass of the pot (soil + water) as well as the water volume corresponding to $100 \%$ of FC. The mass was obtained with an electronic scale (Marte, LC20 model), and the amount of water added was measured using a graduated cylinder. Average values across treatments were compared according to Tukey's test, using the ExpDes statistical package in v2.13.2 of the R software (R Development Core Team).

\section{Primer design}

From the genomic sequence of each of the rice homolog genes from Arabidopsis PLD $\alpha 1$, CesA4, GluR2, CPK5 and $E I N 2$, and the rice control gene Lsil, four primer pairs were designed using the program OligoPerfect ${ }^{\mathrm{TM}}$ Designer (Invitrogen) (Table 4). In order to be able to amplify the transcript sequence, the forward or reverse primers were designed in exon-exon junctions. The criteria adopted for the primer design were a melting temperature ranging from 57 to 63 , a $\mathrm{G}+\mathrm{C}$ content ranging from 20 to $80 \%$ and a product size (amplicon) from 70 to 150 base pairs. The analysis of dissociation curves indicated that all selected primers showed a single PCR product. The reference genes showed close stability values: $A C T(0.010)$; $e E F-1 \alpha(0.011)$, and $G A P D H$ $(0.008)$, and the average $\mathrm{C}_{\mathrm{T}}$ values were similar $(\mathrm{p} \leq 0.05)$.

\section{RNA isolation and quantitative PCR analysis}

Samples of leaf and root tissues of the control and droughtstressed plants were collected on the last day of water restriction of each water-deprivation cycle, immediately placed in liquid nitrogen and stored in a freezer at $-80^{\circ} \mathrm{C}$. Apical leaves (the last fully extended leaf from the top to the base of the main stem) were used as the plant material for total RNA extraction. This extraction was performed with a PureLink ${ }^{\circledR}$ RNA Mini Kit (Ambion $®$ ) according to the manufacturer's instructions. At the end, the total RNA was resuspended in RNAse-free water and stored at $-80^{\circ} \mathrm{C}$. The RNA quantity and integrity were evaluated with the NanoVue $^{\text {TM }}$ (GE Healthcare UK Ltd, England) and the BioAnalyzer 2100 (Agilent Technologies CA, USA), respectively (Table S1 - supplementary material). One microgram of RNA was reverse transcribed using Superscript II reverse transcriptase (Invitrogen ${ }^{\mathrm{TM}}$ ) with the random primer according to the manufacturer's instructions. RTqPCR experiments were conducted using Platinum ${ }^{\circledR}$ SYBR ${ }^{\circledR}$ Green qPCR SuperMix-UDG with ROX (Invitrogen ${ }^{\mathrm{TM}}$ ), and were carried out in a 7500 Real-Time PCR System (Applied Biosystems $\left.{ }^{\circledR}\right)$. The reaction conditions were: $50^{\circ} \mathrm{C}$ for $2 \mathrm{~min}$, $95^{\circ} \mathrm{C}$ for $2 \mathrm{~min}$ followed by 40 cycles at $95^{\circ} \mathrm{C}$ for $15 \mathrm{~s}$ and $60^{\circ} \mathrm{C}$ for $30 \mathrm{~s}$. The total volume of $20 \mu \mathrm{L}$ in each tube contained $2 \mu \mathrm{l}$ of cDNA $\left(5 \mathrm{ng} \mu \mathrm{L}^{-1}\right)$ plus the volume of water. Reverse and forward primers, were variable for each gene, according to the adjustment made for the optimal concentration of each primer (Table S2). All qPCR reactions were performed in triplicate, and the results were analyzed with the DataAssist ${ }^{\mathrm{TM}}$ Software (Life Technologies) based on the delta-delta-Ct method. A heat dissociation curve $\left(60^{\circ} \mathrm{C}\right.$ to $95^{\circ} \mathrm{C}$ ) following the final cycle of the PCR was checked to test the specificity of the PCR amplification. The detection threshold cycle for each reaction was normalized against the 
expression level of the rice reference genes; Actin (ACTX3), Glyceraldehyde-3-phosphate dehydrogenase $(G A P D H)$ and Eukariote Elongation factor $(e E F-1 \alpha)$ genes (Table S3. supplementary material). The gene expression data was compared by Tukey test $(\mathrm{p} \leq 0.05)$, available with the software Statistica v9.0 (StatSoft, Tulsa, OK, USA).

\section{Conclusion}

The expression analysis of rice genes, homologous of Arabidopsis genes previously related to drought tolerance, provided evidence that genes of agronomic interest may have been evolutionarily preserved between these species. In Douradão, of the five homologous genes, all but OsGluR2 increased the average gene expression in the drought treatment compared to the control, while in Primavera, the average expression of the five genes did not differ between the control and drought treatment. In Douradão, the OsPLD $\alpha 1$, which showed the highest expression level in the drought treatment in relation to the control (10.82 times), significantly increased the gene expression in the leaf and root tissues as a response to drought in both vegetative and reproductive stages, whereas in Primavera, this gene was suppressed in both the tissues and stages under drought. Therefore, the OsPLD $\alpha 1$ gene was the most important in relation to drought response and is a candidate for further studies for developing rice cultivars that are more tolerant to this stress.

\section{Acknowledgments}

The authors thank Embrapa for financial support and the Office for Improvement of Higher-Education Personnel/ Ministry of Education (CAPES/MEC) and the National Council for Technological and Scientific Development $(\mathrm{CNPq})$ for the grants awarded.

\section{References}

Ambavaram MMR, Basu S, Krishnan A, Ramegowda V, Batlang U, Rahman L, Baisakh N, Pereira A (2014) Coordinated regulation of photosynthesis in rice increases yield and tolerance to environmental stress. Nat Commun. 5:5302.

Bargmann BOR, Laxalt AM, Riet B, Schooten B, Merquiol E, TesterinkC, Haring MA, Bartels D, Munnik T (2009) Multiple PLDs required for high salinity and water deficit tolerance in plants. Plant Cell Physiol. 50(1):78-89.

Cai K, Gao D,Luo S, Zeng R, Yang J, Zhu X (2008) Physiological and cytological mechanisms of siliconeinduced resistance in rice against blast disease. Physiol Plantarum 134(2):324-333.

Chen W, Yao X, Cai K, Chen J (2011) Silicon alleviates drought stress of rice plants by improving plant water status, photosynthesis and mineral nutrient absorption. Biol Trace Elem Res. 142(1):67-76.

Chen Z, Hong X, Zhang H, Wang Y, Li XI, Zhu J-K, Gong Z (2005) Disruption of the cellulose synthase gene, AtCesA8/IRX1, enhances drought and osmotic stress tolerance in Arabidopsis. Plant J. 43(2):273-283.

Cominelli E, Conti L, Tonelli C, Galbiati M (2013) Challenges and perspectives to improve crop drought and salinity tolerance. Nat Biotechnol. 30(4):355-361.

Counce PA, Keisling TC, Mitchell AJ (2000) A uniform, objective, and adaptive system for expressing rice development. Crop Sci. 40(2):436-443.
Dessimoz C, Gabaldón T, Roos DS, Sonnhammer E, Herrero J (2012) Toward Community Standards in the Quest for Orthologs. Bioinformatics 28(6):900-904.

Fang G, Bhardwaj N, Robilotto R, Gerstein MB (2010) Getting started in gene orthology and functional analysis. Plos Comput Biol. 6(3):e1000703.

Guo L, Wang X (2012) Crosstalk between phospholipase D and sphingosine kinase in plant stress signaling. Front Plant Sci. 3:51.

Holme I, Dionisio G, Brinch-Pedersen H, Wendt T, Madsen CK, Vincze E, Holm PB (2012) A cisgenic approach for improving the bioavailability of phosphate in the barley grain. ISB News Report 8-11.

Hu H, Xiong L (2014) Genetic engineering and breeding of drought-resistant crops. Annu Rev Plant Biol. 65:715-41.

Kamoshita A, Babu RC, Boopathi NM, Fukai S (2008) Phenotypic and genotypic analysis of drought-resistance traits for development of rice cultivars adapted to rainfed environments. Field Crop Res. 109:1-23.

Kim SA, Kwak JM, Jae SK, Wang MH, Nam HG (2001) Overexpression of the AtGluR2 gene encoding an Arabidopsis homolog of mammalian glutamate receptors impairs calcium utilization and sensitivity to ionic stress in transgenic plants. Plant Cell Physiol. 42(1):74-84.

Krasensky J, Jonak C (2012) Drought, salt, and temperaturestress-induced metabolic rearrangements and regulatory networks. J Exp Bot. 63(4):1593-1608.

Li Z, Peng J, Wen X, Guo H (2013) Ethylene-Insensitive3 is a senescence-associated gene that accelerates agedependent leaf senescence by directly repressing miR164transcription in Arabidopsis. Plant Cell 25(9):33113328.

Lu G, Wang X, Liu J, Yu K, Gao Y, Liu H, Wang C, Wang W, Wang G, Liu M, Mao G, Li B, Qin J, Xia M, Zhou J, Liu J, Jiang S, Mo H, Cui J, Nagasawa N, Sivasankar S, Albertsen MC, Sakai H, Mazur BJ, Lassner MW, Broglie RM (2014) Application of T-DNA activation tagging to identify glutamate receptor-like genes that enhance drought tolerance in plants. Plant Cell Rep. 33(4):617-631.

Lu S, Bahn SC,Qu G, Qin H, Hong Y, Xu Q, Zhou Y, Hong Y, Wang X (2013) Increased expression of phospholipase D $\alpha 1$ in guard cells decreases water loss with improved seed production under drought in Brassica napus. Plant Biotechnol J. 11(3):380-389.

Ma JF, Tamai K, Yamaji N, Mitani N, Konishi S, Katsuhara M, Ishiguro M, Murata Y, Yano M (2006) A silicon transporter in rice. Nature 440(7084):688-691.

Ma JF, Yamaji N (2008) Functions and transport oaf silicone in plants. Cell Mol Life Sci. 65(19):3049-3057.

Mishra G, Zhang W, Deng F, Zhao J, Wang X (2006) A bifurcating pathway directs abscisic acid effects on stomatal closure and opening in Arabidopsis. Science 312(5771):264-266.

Mitani N, Yamaji N, Ma JF (2008) Characterization of substrate specificity of a rice silicon transporter, Lsi1. Pflug Arch Eur J Phy. 456(4):679-686.

Mori IC, Murata Y, Yang Y, Munemasa S, Wang YF, Andreoli S, Tiriac H, Alonso JM, Harper JF, Ecker JR, Kwak JM, Schroeder JI (2006) CDPKs CPK6 and CPK3 function in ABA regulation of guard cell S-type anion-and $\mathrm{Ca}(2+)$-permeable channels and stomatal closure. Plos Biol. 4(10):e327.

Patel RV, Nahal HK, Breit R, Provart NJ (2012) BAR expressolog identification: expression profile similarity ranking of homologous genes in plant species. Plant $\mathbf{J}$. 71(6):1038-1050. 
Sang Y, Zheng S, Li W, Huang B, Wang X (2001) Regulation of plant water loss by manipulating the expression of phospholipase D $\alpha$. Plant J. 28(2):135-144.

Shobbar ZS, Oane R, Gamuyao R, De Palma J, Malboobi MA, Karimzadeh G, Javaran MJ, Bennett J (2008) Abscisic acid regulates gene expression in cortical fiber cells and silica cells of rice shoots. New Phytol. 178(1):68-79.

Singh A, Pandey A, Baranwal V, Kapoor S, Pandey G (2012) Comprehensive expression analysis of rice phospholipase $\mathrm{D}$ gene family during abiotic stresses and development. Plant Signal Behav. 7(7):847-855.

Thole JM, Beisner ER, Liu J, Venkova SV, Strader LC (2014) Abscisic acid regulates root elongation through the activities of auxin and ethylene in Arabidopsis thaliana. G3 (Bethesda) 4(7):1259-1274.

Uraji M, Katagiri T, Okuma E, Ye W, Hossain MA, Masuda C, Miura A, Nakamura Y, Mori IC, Shinozaki K, Murata Y (2012) Cooperative function of PLD $\delta$ and PLD $\alpha 1$ in abscisic acid-induced stomatal closure in Arabidopsis. Plant Physiol. 159(1):450-460.

Wang J, Ding B, Guo Y, Li M, Chen S, Huang G, Xie X (2014) Overexpression of a wheat phospholipase D gene, TaPLD $\alpha$, enhances tolerance to drought and osmotic stress in Arabidopsis thaliana. Planta 240(1):103-115.

Wang Y, Liu C, Li K, Sun F, Hu H, Li X, Zhao Y,Han C, Zhang W, Duan Y, Liu M, Li X (2007) Arabidopsis EIN2 modulates stress response through abscisic acid response pathway. Plant Mol Biol. 64(6):633-644.
Watkins JM, Hechler PJ, Muday GK (2014) Ethyleneinduced flavonol accumulation in guard cells suppresses reactive oxygen species and moderates stomatal aperture. Plant Physiol. 164(4):1707-1717.

Xian L, Sun P, Hu S, Wu J, Liu JH (2014) Molecular cloning and characterization of $C r N C E D 1$, a gene encoding 9-cisepoxycarotenoid dioxygenase in Citrus reshni, with functions in tolerance to multiple abiotic stresses. Planta 239(1):61-77.

Xiong X, Schumaker KS, Zhu JK (2002) Cell signaling during cold, drought and salt stress. Plant Cell 14Suppl:S165-183.

Xu J, Tian YS, Peng RH, Xiong AS, Zhu B, Jin XF, Gao F, Fu XY, Hou XL, Yao QH(2010) AtCPK6, a functionally redundant and positive regulator involved in salt/drought stress tolerance in Arabidopsis. Planta 231(6):1251-1260.

Yan C, Yan S, Zeng Z, Zhang Z, Gu M (2007) Fine mapping and isolation of $B c 7(t)$, allelic to OsCesA4. J Genet Genomics 34(11):1019-1027.

Yang C, Li D, Liu X, Ji C, Hao L, Zhao X, Li X, Chen C, Cheng Z, Zhu L (2014) OsMYB103L, an R2R3-MYB transcription factor, influences leaf rolling and mechanical strength in rice (Oryza sativa L.). BMC Plant Biol. 14:158. 